\title{
Aproximación al estudio de las formas de representación de los actores armados en la Ley de Justicia y Paz en Colombia*
}

\author{
Approach to representations of armed actors in Justice \\ and Peace Law in Colombia
}

María Teresa Suárez González

Doctoranda en Lenguaje y Cultura, Universidad Pedagógica y Tecnológica de Colombia-UPTC mariateresasuarezgonzalez@gmail.com

Artículo de investigación

Fecha de recepción: Julio 28 de 2015• Fecha de aprobación: Noviembre 21 de 2015

\section{RESUMEN}

El propósito del presente artículo es presentar una aproximación a la manera como se construyen los actores discursivos en la Ley 975 de 2005 (Ley de Justicia y Paz) en Colombia. Se toman como base los procesos de inclusión y exclusión de actores, desde estrategias lingüísticas soportadas en recursos de diversa índole.

El proceso investigativo comprometió tres fases: a) Descripción del corpus y proceso analítico, a partir de la estadística textual, identificación de recursos y estrategias, construcción de categorías; b) Análisis de resultados; c) Interpretación de resultados en clave social y cultural.

Palabras clave: Ley de Justicia y Paz, actores discursivos, transformación discursiva, neutralización.

* El trabajo hace parte de la tesis doctoral Representaciones de Justicia y Paz en la Ley 975 de 2005: análisis discursivo y social, cuya dirección está a cargo de Neyla Graciela Pardo Abril, docente titular, Universidad Nacional de Colombia. 


\section{AbSTRACT}

The following text presents an approach to the forms in which discursive actors are built in the law 975 of 2005 (Justice and Peace Law). The inclusive and exclusive processes of actors and diverse linguistic strategies are taken into account.

The research process comprehends three phases: a) Corpus description and analytic process based on textual statistics, resource and strategies identification and categories construction; b) Analysis of results; c) Interpretation of results from a social and cultural perspective.

Keywords: Justice and Peace Law, discursive actors, discursive transformation, neutralization. 


\section{INTRODUCCIÓN}

La construcción del actor discursivo permite establecer aspectos del núcleo de la representación. La manera como se construyen en este trabajo presenta una aproximación a la construcción discursiva del actor armado, desde dos procesos: inclusión y exclusión, que permiten evidenciar la manera como se construyen formas de representar al actor en el discurso de la Ley 975 de 2005, la cual dio inicio a lo que en Colombia se denomina el proceso de Justicia y Paz con los paramilitares.

Así, mediante el proceso de inclusión se visibilizan unos actores del conflicto, y con la exclusión se construyen diversas formas de ocultamiento no solamente de los actores, sino de sus acciones pasadas o de sus responsabilidades futuras.

Se busca explicar cómo se hace una construcción del actor armado desde estrategias que buscan borrar las acciones pasadas de violación de los derechos humanos, las cuales justifican la aplicación del proceso de justicia transicional y sitúa al actor armado como propiciador de unas acciones mostradas como positivas, a futuro.

\section{Notas en torno a la Justicia Transicional}

El discurso de la Justicia Transicional tiene buena parte de sus orígenes en el Estatuto de Roma, por medio del cual se crea la Corte Penal Internacional. El estatuto contempla los diferentes tipos de delitos de violación contra los derechos humanos hacia la población civil, plantea los casos en los cuales la corte podrá intervenir y la aplicación de unos instrumentos especiales de justicia en naciones que se encuentran en un tránsito de una dictadura a una democracia, o que han tenido un conflicto armado prolongado en el tiempo y que, por su complejidad, no ha podido ser resuelto, ni puede ser tratado por la justicia ordinaria de esa nación.

En este marco surge la figura de la Justicia Transicional, definida no como un tipo de justicia, sino como un conjunto de mecanismos adaptados a las realidades que requieren las naciones para que se dé el proceso de transición-CJT- (ICTJ, 2016). Así, en el proceso de transición se asume que dentro de las metas por alcanzar se 
encuentran la democracia y una paz que perdure en el tiempo, lo cual supone la reconciliación nacional.

Los objetivos que plantea la aplicación de este instrumento tienen como centro a las víctimas y sus derechos, el fomento a la confianza cívica, la contribución a la reconciliación y el fortalecimiento del estado de derecho. De ahí que el sentido de aplicación de la transición imponga necesariamente:

Unos procesos a través de los cuales se realizan transformaciones radicales de un orden social y político, bien sea por el paso de un régimen dictatorial a uno democrático, bien por la finalización de un conflicto interno armado y la consecución de la paz (Uprimny, 2006, p. 13).

El centro de aplicación del proceso son las víctimas, por ello es que en los procesos transicionales los aspectos fundamentales para que se haga efectiva la justicia transicional, implique que quienes hayan sido responsables de violaciones a los derechos humanos y se acojan al proceso, deban cumplir unos requisitos previos para la debida reparación a las víctimas y puedan alcanzar la pena alternativa. El antecedente del proceso de Justicia y Paz en Colombia fueron las negociaciones adelantadas por el gobierno de Álvaro Uribe Vélez con miembros de las Autodefensas Unidas de Colombia en Santafé de Ralito (Antioquia). El proceso de negociación firmado en el 2003 trajo como consecuencia que en ese año en Medellín iniciara el proceso el bloque Cacique Nutibara y finalizara en el 2006 con el bloque Elmer Arenas.

En una entrevista realizada a semana.com en el 2008, Luis Jorge Garay explica que el Pacto de Ralito fue un proceso político que buscó reestructurar el Estado a partir de la promulgación de la Ley 975 de 2005. La vía política permite, según Garay (Semana, 2008):

Intervenir, interferir y mediar para reconfigurar el Estado, en este caso a nuevas prácticas que se proponen desde lo rural. Primero es con los grupos tradicionales y luego encuentran que es más efectivo hacerlo a través de nuevas organizaciones políticas que les permiten insertarse más fácilmente en el Estado, Esto explica por qué la expansión paramilitar (semana.com). 
En sus estudios sobre violencia y guerra, Granada, Restrepo y Tobón (2009) plantean que la efectividad de una negociación con un grupo armado requiere un efectivo proceso de justicia transicional, para que se dé el imperativo de la justicia y la sostenibilidad de los acuerdos alcanzados, lo cual implica la desactivación de la guerra con estos grupos. El estudio realizado muestra que, si bien se logró una desmovilización de miembros de grupos armados, el aparato de guerra continuó activo, al menos parcialmente, y evidencia de ello se encuentra en lo que se ha denominado los grupos "neoparamilitares", o las Bandas Criminales Emergentes - Bacrim, las cuales han tenido diversos orígenes, que pasan por el rearme de los grupos que se desmovilizaron producto de los acuerdos, la deserción del proceso y de la expulsión de Justicia y Paz por incumplimiento, por parte de los actores armados, entre otros aspectos.

\section{ALGUNOS PRESUPUESTOS TEÓRICOS Y METODOLÓGICOS}

La construcción de significados, además de ser producto de la experiencia humana, también lo es a nivel social y pasa por los diversos discursos que circulan en dichas sociedades. Desde la perspectiva crítica, los estudios del discurso proponen formas de explicación de fenómenos sociales que tienen que ver con órdenes cognitivos. Es por ello que los discursos, articulados a las prácticas sociales, se constituyen en una representación de algún aspecto de la realidad y ello incluye un conjunto de cogniciones individuales y sociales de quienes los producen y quienes construyen los diferentes significados (Pardo, 2008).

Se asume que los discursos, conceptualmente, estructuran formas de preservación de los distintos órdenes sociales, políticos y jurídicos, entre otros, por ello se reconoce también la necesidad de desentrañar los sentidos y significados sobre los cuales se construye dicha preservación, los cuales inciden en la configuración, tipos de representaciones del mundo y distintos órdenes cognitivos.

Si se parte de asumir que las Representaciones Sociales (RS) son sistemas de conocimiento socialmente compartidos, su relación con los discursos se establece, precisamente, a partir de este último como lugar desde donde se orienta la acción 
social. Las RS se materializan en las maneras en que los grupos construyen sus opiniones, creencias y actitudes, entre otros muchos aspectos de la vida en sociedad (Moscovici y Hewstone, 1984; Abric, 2011).

En este caso, el estudio se centró en visibilizar cómo se proponen representaciones sociales acerca de la justicia en la Ley 975 de 2005, desde la construcción de actores discursivos, puesto que las teorías de las RS plantean que una manera de establecer los aspectos del núcleo central están en la construcción de identidades (Abric, 2011), ligadas a los actores, en este caso, los discursivos.

La importancia del estudio de las leyes, en tanto discursos que rigen buena parte de la vida social de los individuos en la sociedad, encuentra sustento en lo que Pierre Bourdieu (2000) plantea acerca de la metáfora de la "palabra divina", o la palabra contenida en las leyes, la cual se asume como un tipo de autoridad delegante, es decir una autoridad que es delegada en el discurso mismo por quienes lo producen y aprueban. Las leyes, desde esta perspectiva, se sitúan en una "Justicia Normal" (Fraser, 2008), asumida desde elementos de obediencia y aparente consenso para preservar un determinado orden social, político o económico y, también, el discurso jurídico es a su vez, como lo plantea Foucault (2010), un lugar de lucha, "aquel poder del que quiere uno adueñarse” (p. 15), para alcanzar unos fines específicos.

El apartado metodológico privilegió el enfoque mixto, con prevalencia cualitativa, a partir de los insumos arrojados por el programa T-Lab, el cual permitió la organización gráfica y estadística del corpus abordado, para el posterior análisis, en donde los procesos inferenciales son insumo para la construcción de categorías y el análisis discursivo social. Como lo indica Pardo (2008), quien plantea que los procesos inferenciales están construidos sobre un conjunto de razonamientos que se articulan con diversas formas lingüísticas y niveles de representación de la realidad.

El proceso de investigación asumió los postulados teóricos y metodológicos de los Estudios Críticos del Discurso (Antaqui, Billig y Potter, 2003), lo cual implica que los discursos, cualquiera que sea su naturaleza, requieren de una fragmentación en sus unidades mínimas para desentrañar los sentidos que subyacen, a partir de los datos que arrojan las herramientas de estadística textual. La construcción cualitativa 
busca es interpretar los datos a la luz del contexto, asumiéndolo como los tipos de modelos mentales, es decir, como "esquemas de categorías convencionales, compartidas y que dependen de la cultura, las que permiten interpretaciones rápidas de los acontecimientos comunicativos en proceso" (Van Dijk, 2012, p. 40).

Se tomó como unidad de análisis el discurso jurídico para evidenciar algunos sistemas de conocimiento que refuerzan el sustento y la preservación de un orden político y social con los grupos armados para quienes fue creada dicha ley. El orden social hace referencia a construcciones sociales, producto de actividades humanas pasadas (Berger y Luckmann, 2001) y tiene como antecedente la institucionalización de comportamientos, es decir la naturalización y normalización de actuaciones de los grupos para ser mayormente controlados.

Así, en los discursos es posible establecer diversas formas en que se configuran los contextos (Van Dijk, 2012), no solamente como aspectos externos al discurso, sino como conjuntos de modelos mentales que, al ser compartidos en los grupos, inciden en la conformación de creencias, valoraciones por el mundo y formas de actuar.

\section{Actores discursivos}

La categoría actor discursivo abreva de la propuesta de Theo Van Leeuwen (1996), para quien un actor discursivo se constituye como agente o como paciente de acciones específicas dentro de la situación discursiva. El actor es posible rastrearlo en el discurso desde, al menos, tres perspectivas: a) presencia de voces, b) formas de nominarlos (Searle, 1991) y c) acciones con las cuales se relaciona. Estos aspectos permiten evidenciar cómo desde los procesos de inclusión y exclusión (Van Leeuwen, 1996) se constituyen formas de representación de los actores.

En el primer caso expuesto, la presencia de voces incide en la construcción de formas de representar a los sujetos y de autorrepresentarse en la situación discursiva (Bajtín, 2011). En el proceso analítico y descriptivo del corpus fue posible evidenciar voces que se atribuyen las acciones, como el Congreso de la República, Álvaro Uribe Vélez, Ministro del Interior y de Justicia, Sabas Pretelt de la Vega (las palabras con énfasis hacen parte 
de los ejemplos extraídos del corpus), las cuales aunque, en apariencia, son diferentes, obedecen a un mismo enunciado, a partir de formulas heteroglósicas (Bajtín, 2011).

En el corpus se evidenció que la presencia de voces tiene como consecuencia cognitiva una propuesta de integración (Jodelet, 1986). La integración está en la unificación de lugares de enunciación que proponen un sistema de conocimiento encaminado al consenso y, por tanto, a la condición de veracidad y universalidad que, de por sí, trae consigo la aprobación e implementación de la ley y las consecuencias sociales que ha tenido la aplicación del proceso transicional; así el proceso no sea legitimado por grupos sociales, específicamente por las organizaciones de víctimas y sectores de la academia y el ámbito jurídico.

En el objeto de la ley 975 de 2005 se plantea:

La presente ley regula lo concerniente a la investigación, procesamiento, sanción y beneficios judiciales de las personas vinculadas a grupos armados organizados al margen de la ley, como autores o partícipes de hechos delictivos cometidos durante y con ocasión de la pertenencia a esos grupos, que hubieren decidido desmovilizarse y contribuir decisivamente a la reconciliación nacional (p. 1).

En este caso, las construcciones metonímicas (desde la perspectiva cognitiva de Lakoff y Johnson (1986) plantean que buena parte del sistema conceptual de los sujetos es de naturaleza metafórica o metonímica. En este caso la metonimia, en tanto recurso lingüístico, se configura desde una función referencial) representadas sobre la base del concepto "la institución por la gente responsable" (Lakoff y Johnson, 1986, p. 76), en la expresión "la presente ley", se evidencian, al menos dos aspectos: uno que tiene que ver con la legalidad y condición de veracidad de la figura de la ley para alcanzar el reconocimiento político de los grupos armados al margen de ley; el otro es un ocultamiento de los proponentes, quienes se ocultan en la figura de "la presente ley", la cual es representada como un actor, cuya autoridad deriva en un aparente consenso en relación con la legalidad de la puesta en marcha del proceso transicional en este periodo en Colombia. Este aspecto se refuerza en las altas frecuencias de parición de la unidad léxica "Ley", como se aprecia en la tabla 1. 
Tabla 1. Frecuencias de unidades léxicas.

\begin{tabular}{|l|c|}
\hline \multicolumn{2}{|c|}{ Altas frecuencias } \\
\hline \multicolumn{1}{|c|}{ U. Léxica } & Frecuencia \\
\hline ley & 206 \\
\hline artículo & 114 \\
\hline víctima & 90 \\
\hline presenter & 67 \\
\hline nacional & 65 \\
\hline grupo & 64 \\
\hline reparación & 60 \\
\hline sentencia & 48 \\
\hline judicial & 47 \\
\hline armado & 45 \\
\hline
\end{tabular}

\begin{tabular}{|l|c|}
\hline \multicolumn{2}{|c|}{ Altas frecuencias } \\
\hline \multicolumn{1}{|c|}{ U. Léxica } & Frecuencia \\
\hline derecho & 45 \\
\hline corte & 40 \\
\hline margen & 39 \\
\hline constitucional & 39 \\
\hline mediante & 38 \\
\hline justicia & 35 \\
\hline cargo & 35 \\
\hline declarado & 31 \\
\hline público & 29 \\
\hline pena & 29 \\
\hline
\end{tabular}

Fuente: elaboración propia con base en datos de la estadística textual.

Nota: nótese la diferencia entre la primera frecuencia y aspectos del proceso de transición como son la víctima, la reparación, la sentencia, la justicia, la pena.

Lo anterior permite rastrear propósitos de la producción discursiva y de lo que se quiere reiterar, aspectos que hacen parte del contexto de la producción (Van Dijk, 2012), es decir el conjunto de modelos mentales que construyen los individuos de manera subjetiva, que inciden en la conformación de cogniciones más amplias que constituyen el sistema de creencias y maneras de valorar el mundo por parte de determinados grupos sociales. En este caso la orientación del discurso se encamina a mostrar que este es consensuado, amparado en una estructura mayor que es la ley y permite dar cuenta del lugar que se otorga a los actores que son reconocidos y validados socialmente mediante un proceso democrático.

La relevancia semántica en la presencia de voces está dada en mostrar diversos actores, en una aparente pluralidad, cuya enunciación incide en la activación de 
saberes respecto del lugar que se le otorga a la justicia en el proceso de transición, desde la unificación de enunciados que corresponden a un mismo lugar ideológico.

Hasta aquí se han planteado algunas consecuencias sociales de la presencia de voces en un discurso. Este aspecto guarda relación con otro que determina el lugar, desde donde se representa a los actores. Lugar este que tiene que ver con las formas de nombrar a los sujetos dentro del discurso. Así, la nominación, en tanto estrategia discursiva, permite rastrear no solo la producción del discurso, sino establecer aspectos que refuerzan las formas en que representa al actor y por tanto de construcción de su identidad.

La construcción simbólica de procesos de distinción de unos actores en relación con otros, dentro de la situación misma define, en buena medida, también las acciones que les son asignadas y las responsabilidades por sus actos (Van Leeuwen, 1996).

\section{Exclusión: lo que hay detrás de un nombre}

En su acepción más general la exclusión es un fenómeno en el cual los sujetos o grupos de sujetos pierden o les es negada la capacidad de participación en escenarios de diversa índole. En la situación discursiva de la Ley de Justicia y Paz se evidenció que la exclusión de actores se presenta cuando no se nombra, por ejemplo, a los paramilitares, actores estos que desde la década de los años 60 del siglo pasado hicieron parte constitutiva del conflicto armado colombiano, aunque entre 1997 y 2003 se haya dado el mayor crecimiento y expansión del paramilitarismo en Colombia (Valencia, 2007).

El ocultamiento de esta nominación de actores marca un aspecto relevante en la configuración de los actores discursivos de la ley, inclusive en el proceso de aplicación de la Justicia Transicional, que supone la entrada a una negociación con fuerzas que han actuado por fuera de la ley, cuyo accionar estuvo amparado por diversos actores que actuaron dentro de los marcos del Estado. De lo anterior es posible establecer:

a) El no reconocimiento de los grupos paramilitares, desde estrategias de ocultamiento, como actores constitutivos del conflicto armado colombiano, 
borra por completo los hechos de victimización, así como las responsabilidades (políticos, funcionarios del Estado, empresarios y la fuerza pública, entre otros) en la creación y sustento de los grupos, así como de la preservación de los derechos humanos de los ciudadanos colombianos por parte de los entes gubernamentales.

b) El desconocimiento de la existencia de los paramilitares impide que en la realidad y puesta en marcha del proceso de Justicia y Paz, sea posible el desmonte del paramilitarismo en Colombia.

La supresión, en tanto estrategia ayuda al propósito de borrar totalmente la huella de este actor sustantivo del conflicto armado colombiano (paramilitar), bien sea porque no se nombra o porque no existe una relación con sus responsabilidades directas. Al invisibilizarlo se hace difícil el rastreo de sus acciones pasadas y futuras en la situación del discurso, cuya consecuencia de aplicación de la ley propende a la construcción de unas representaciones de la justicia encaminadas a ocultar las acciones pasadas de este grupo, en el marco del conflicto armado colombiano.

Estos aspectos ponen en evidencia unas tensiones entre lo propuesto en la ley y el proceso de justicia transicional, si se tiene en cuenta que la aplicación de la ley implica el reconocimiento de la existencia de un conflicto armado prolongado con violaciones sistemáticas a los derechos humanos. La tensión que se evidencia precisamente está en el interés político de la formulación y ello conlleva a una actitud utilitaria del mecanismo de transición, con el "propósito de lograr y ocultar la impunidad. Se trata de un uso manipulador de la justicia transicional, en la medida en que el lenguaje jurídico resulta simplemente retórico, no lleva a cabo ninguna transformación material o práctica" (García, Revelo y Uprimny, 2015, p. 319). Estos autores plantean otra característica que está dada en la naturaleza "democrática o emancipatoria" (2015, p. 319), cuyo aspecto deóntico privilegia la lucha contra la impunidad y su carácter emancipatorio le otorga a las víctimas el reconocimiento que han perdido desde el mismo hecho de victimización o revictimización, puesto que la emancipación reconoce las relaciones simétricas que deben existir entre víctimas y victimarios, cuya disparidad se ha dado precisamente por el sometimiento del que 
Campos en Ciencias Sociales

El desarrollo y su complejidad desde las perspectivas multidisciplinar y transdisciplinar

han sido objeto las víctimas por parte de los grupos al margen de la ley. En este caso en la representación que se evidencia de los actores armados.

\section{¿A quiénes se incluye?}

En la inclusión, la nominación ayuda a visibilizar y representar al actor de maneras diversas (ver tabla 2).

Tabla 2. Nominación actores armados.

\begin{tabular}{|l|l|}
\hline Tipos de actores & \multicolumn{1}{c|}{ Formas en que se nombra } \\
\hline Actores armados & $\begin{array}{l}\text { Miembros de grupos armados al margen de la ley, grupo armado } \\
\text { organizado al margen de la ley, el grupo de guerrilla o de } \\
\text { autodefensas, persona individual, persona colectiva, integrante, } \\
\text { personas responsables, miembros de un grupo, acusados, } \\
\text { condenados, autores, partícipes, procesados, imputado, personas } \\
\text { vinculadas a grupos armados, personas que puedan ser favorecidas, } \\
\text { desmovilizado al grupo armado organizado al margen de la ley, } \\
\text { imputado, acusado. }\end{array}$ \\
\hline
\end{tabular}

Fuente: elaboración propia con base en datos de la estadística textual.

En los ejemplos presentados en la tabla 2 se aprecian diversas formas de nombrar al actor armado en Justicia y Paz, ello obedece también a las acciones con las cuales se vincula, es decir, las dimensiones del discurso no solamente como prácticas que se proponen, sino en las secuencias de actos que están relacionadas de manera directa (Van Dijk, 2005). Este aspecto determina, en buena medida, la posición que se le otorga dentro del discurso y las condiciones y propósitos de su producción del mismo.

La inclusión de actores discursivos, construidos sobre recursos de nominación, como miembros de grupos armados al margen de la ley, grupo de guerrilla o de autodefensas (ver tabla 2), propone unos sistemas de conocimiento respecto de, al menos, dos aspectos.

a) Reconocimiento de la existencia de grupos antagónicos al Estado, a quienes se les reconoce, también, como actores políticos del conflicto y con quienes es 
María Teresa Suárez González Aproximación al estudio de las formas de representación de los actores armados en la Ley de Justicia y Paz en Colombia

necesario entablar una negociación, en razón a que no fueron derrotados por las fuerzas del Estado.

b) La construcción metonímica "las partes por el todo" y "el todo por las partes" (Lakoff y Johnson, 1986), mediante estrategias de asociación (cuando se nombra a individuos incluidos dentro de grupos sociales, gracias a que comparten características similares, sin que exista la posibilidad de rastrear sujetos en específico), ayuda al propósito de incluir en un mismo universo los grupos antagónicos cuya existencia propia se justifica en la existencia del otro, sin que sea posible establecer sus diferencias. Dichas diferencias, entre los grupos de guerrilla y las autodefensas, se pueden explicar de diversas maneras. Los primeros han sido considerados históricamente enemigos del Estado y surgen como respuesta a aspectos de injusticia social. Geográficamente, su ubicación está en las selvas de Colombia; mientras que los segundos tienen una legitimidad y aprobación parcial por parte del estado. López (2015) explica que parte de la razón de ser del paramilitarismo (como ellos lo han expresado), sustenta su existencia en "la defensa de la propiedad, sobre todo rural, contra la guerrilla, pero también contra cualquier forma de protesta y ciertamente contra muchas modalidades de presencia de regulación del Estado” (p. 17).

Este aspecto es fundamental para la comprensión de lo que ha sido el conflicto armado colombiano y la existencia de los grupos de autodefensa en Colombia.

La representación que subyace a los procesos de inclusión se encamina a reforzar la precaria comprensión de lo que ha sido el origen del conflicto armado colombiano y el accionar de cada uno de los grupos, para que pueda configurarse un proceso de construcción de paz, como se asume en un proceso de Justicia Transicional.

El uso de frases indeterminadas como personas vinculadas a grupos armados, autores $o$ participes de hechos delictivos, refuerza el propósito de representar a los actores de manera contraria a la realidad del conflicto armado colombiano.

En el caso por ejemplo de los orígenes de las Farc, Alfredo Molano presenta una radiografía del tema de la tenencia de las tierras y la explotación por parte de los 
campesinos, especialmente de Tierradentro y Chaparral con la lucha de Quintín Lame, quien en 1922 comenzó la lucha indígena por lo que se consideraba la devolución de tierras a los indígenas, las cuales habían sido objeto de despojo desde la época de la colonia por parte de los españoles. Las luchas de Lame fueron armadas, pero también legales, sin que se obtuvieran resultados positivos, como se aprecia en la realidad. Un segundo aspecto que deja en evidencia el problema de la tenencia de la tierra y del despojo, tiene que ver con la colonización campesina de la cordillera central después de la guerra de 1876, por parte de campesinos desplazados provenientes del Quindío, quienes llegaron al norte del Tolima y fundaron pueblos como el Líbano, Padua y Fresno, lo cual hizo que entraran en conflicto con las haciendas cafeteras, cuya expansión territorial iba en aumento hacia terrenos baldíos (Molano, 2016).

En este caso, la estrategia de reordenamiento, que propende a un cambio de rol del actor y por tanto su ubicación en el discurso, cambia el papel inicial del actor armado como causante de hechos de violencia sistemática sobre diversas poblaciones del país. Representar el actor discursivo como partícipe de hechos delictivos mediante el uso de eufemismos (este, en tanto recurso lingüístico, baja la carga de significado de una acción para simplificar el hecho), simplifica las acciones pasadas y pone en un mismo lugar discursivo los hechos delictivos, que podrían ser juzgados por la justicia ordinaria y no requerirían de procesos de justicia transicional. Así, se refuerza el ocultamiento de las violaciones masivas a los derechos humanos y las personas responsables, aspecto este que le posibilita a la nación aplicar el proceso de justicia transicional.

Desde el punto de vista cognitivo, la desmovilización en Justicia y Paz (artículo 9. $\left.{ }^{\circ}\right)$ representa y propone un sistema de conocimiento de un actor anónimo que se infiere corresponde al actor armado, construido sobre el carácter de la voluntad del implicado. Así, en la definición de la desmovilización se plantea esta como el acto individual o colectivo de dejar las armas y abandonar el grupo armado organizado al margen de la ley, realizado ante autoridad competente, la representación del actor armado se configura desde procesos de activación, término que hace referencia a un proceso en el cual el actor discursivo tiene un papel activo en la situación discursiva. Van Leeuwen (1996) plantea que la pasivación es un proceso mediante el cual se representan los actores como receptores de acciones ofrecidas por otros con capacidad 
de movimiento, es decir, como agente de la dejación de armas y del abandono del grupo armado; se elide la responsabilidad de ante quién se realiza la desmovilización y se estabiliza una marca de autoridad abstracta. Con esto, la responsabilidad de la verificación del proceso mismo se deja en un agente universal que legaliza el proceso de desmovilización, pero cuyo rostro se oculta en virtud de la autoridad delegada. Construcciones como estas inciden en la estabilización de unas formas de conocimiento respecto de la responsabilidad del Estado y de las autoridades en el proceso que antecedió a la aplicación de Justicia y Paz: la desmovilización.

Este aspecto representa al Estado y a la sociedad en general lejanos de la veeduría del desmonte de los grupos, como se está reconociendo en la actualidad con el accionar de bandas criminales, como las denomina el gobierno, cuya creación ha tenido como uno de los antecedentes el proceso de desmovilización iniciado en el 2003.

En el artículo 3 de la ley se expone el tema de la alternatividad, es decir, la pena alternativa que recibirán los grupos por acogerse a la ley, la cual se construye sobre la base de unos actores que se representan como pacientes y como agentes de la situación discursiva.

Los procesos de inclusión y exclusión de aplicación de la pena alternativa se configuran de la siguiente manera: como paciente, es decir como receptor de unas acciones buenas otorgadas por un actor anónimo, que se infiere es la ley o sus proponentes: alternatividad es un beneficio consistente [...]; y como agente, es decir como propiciador de unas acciones positivas, planteadas desde la contribución a la consecución de la paz nacional, la reparación a las victimas y su adecuada resocialización. La aplicación de la pena alternativa se construye a partir de un proceso de reordenamiento discursivo o cambio de roles de los actores, cuya base es el uso de estrategias de supresión, con el propósito de cambiar radicalmente las acciones iniciales, es decir, las responsabilidades de las violaciones masivas a los derechos humanos y proponerlos como propiciadores de acciones positivas sobre otros, que en este caso son las víctimas y la nación en general.

La locución verbal contribución a la consecución (hace referencia a la unión de dos verbos, en la cual uno de los dos pierde su condición verbal) refuerza el propósito de 
otorgar a los actores discursivos un lugar radicalmente diferente al que tuvieron en el marco del conflicto armado y, de esta manera, se traslada el aspecto deóntico, es decir, las responsabilidades éticas y morales de lo que implica, también, el acceso a la justicia transicional, para una condición volitiva y condicionante de unos actores, mediante una estrategia de neutralización, la cual sirve al propósito de transformar el conflicto inicial de victimización por unas acciones generosas soportadas en la contribución y la resocialización de las víctimas. Por neutralización se entiende la estrategia por medio de la cual se busca la eliminación del conflicto inicial, sustituyéndolo por otro cuya carga semántica puede ser opuesta. "Es la anulación cognitiva de las percepciones sobre fenómenos sociales específicos, que pueden considerarse peligrosos en un orden social determinado" (Pardo, 2013, p. 159).

De esta manera, se configura un universo metafórico en el cual "el agente tiene un cambio positivo sobre el paciente" (Lakoff y Johnson, 1986, p. 110) se borran las acciones pasadas y se ubica al actor armado como responsable de unas acciones futuras, que redundarán en un estado de bienestar abstracto.

Representar a los actores armados como contribuyentes de acciones positivas propone unas cogniciones sociales en las cuales se desconoce las acciones pasadas y el lugar histórico de estos actores en el conflicto, la problemática de tenencia de la tierra, el despojo, entre otros muchos aspectos que hacen parte de la entrańa del conflicto armado.

En la colaboración con la justicia debe estar encaminada a lograr el goce efectivo de los derechos de las victimas a la verdad, la justicia, la reparación y la no repetición. La acción de colaboración anula la percepción inicial del fenómeno de victimización. Sitúa al actor como agente en cuya voluntad queda el alcanzar el estado de felicidad de otros (víctimas). La construcción representa al actor dotado de generosidad y agenciamiento para que otros tengan acceso a los derechos planteados en Justicia y Paz. Estas construcciones simplifican los derechos que tienen las víctimas a conocer la verdad, a la reparación y a la justicia y la no repetición de los hechos como se plantea en el proceso de transición. Basta ver el documental del periodista Hollman Morris y Juan José Lozano (2012), Impunity, para conocer la dimensión de lo que ha sucedido con los procesos de Justicia y Paz en el país, en donde en las audiencias 
se muestra a los actores armados dotados de toda capacidad para confesar lo que consideran pertinente, y la impotencia de las víctimas al no conocer la verdad de los hechos. El documental muestra cómo la Ley de Justicia y Paz ha ayudado a mantener el orden social y el cambio radical que supone el proceso de transición no se hace evidente, precisamente porque el debate central de la aplicación del proceso no se ha dado en Colombia.

\section{APROXIMACIÓN AL ANÁLISIS DISCURSIVO SOCIAL}

Si se parte de comprender que la justicia necesariamente debe invocar la paridad de participación de los sujetos en una situación de injusticia como lo plantea Fraser (2008), y que el proceso de aplicación de Justicia Transicional en Colombia implica unos cambios radicales en el orden establecido para alcanzar, en este caso, la paz, el estudio de la representación de los actores discursivos en la Ley de Justicia y Paz muestra precisamente todo lo contrario.

Las razones están dadas en, al menos, tres aspectos:

- Si bien es cierto que el proceso de transición implica la creación de unas condiciones especiales de aplicación de la justicia en casos de violación sistemática a los derechos humanos, lo propuesto en el corpus analizado acerca de la ubicación de los actores deja ver la emergencia de unos elementos de impunidad, en la medida en que el proceso de transformación discursiva ayuda al propósito de borrar las acciones pasadas que ocasionaron los hechos de victimización, situando al actor como propiciador de otras acciones mostradas como positivas, a futuro.

Ello implica que se propone un actor armado cuyas acciones pasadas de violación sistemática de los derechos humanos queda invisibilizada. El reconocimiento político está dado en acciones futuras de dejación de armas y de colaboración con la justicia para la consecución de la paz y la reconciliación nacional; acciones estas mostradas de manera positiva. El agenciamiento del 
actor armado se sustenta en la acción volitiva de desarme inicial y como propiciador de unas acciones positivas hacia las víctimas y hacia la sociedad.

Las acciones generosas a futuro, con las cuales se representa el actor armado, impiden reconocer el pasado y con ello se borra el lugar de la memoria como aspecto fundamental del compromiso de no repetición, que trae consigo la justicia transicional para alcanzar un estado de paz.

- La realidad de aplicación de la Ley de Justicia y Paz ha mostrado que los temas de la justicia, junto con los de la transición, pese a estar instalados en diversos escenarios de la vida del país, requieren de una construcción de sentidos que vinculen dichas temáticas también con las maneras como vive la sociedad su vida. Esto implica la necesidad de que la transición permita el reconocimiento de diversas problemáticas sociales, políticas y ambientales que han sido fundamento del conflicto armado, como el despojo de tierras, el desplazamiento de familias de sus lugares de origen, el favorecimiento hacia las multinacionales que han obtenido beneficios económicos de territorios que han sido despojados. El ocultamiento de estos temas o su precaria visibilización, han incidido en el refuerzo de la preservación del orden establecido y ha posibilitado que el conflicto armado colombiano haya alcanzado dimensiones de degradación humana que aun como sociedad no ha sido posible debatir y comprender, lo cual ha incidido también en el desdibujamiento de la necesidad de un cambio como sociedad que impida que los hechos se repitan y que se busque una justicia más social.

La idea de justicia está vinculada de manera estrecha con el sistema de saberes en relación con que esta dota a los actores armados de unas características lejanas a la realidad de lo que ha sido en Colombia el conflicto armado. Se borran no solamente las responsabilidades del Estado en la preservación de los derechos de los ciudadanos, en el conflicto armado en general, si no que se ocultan las acciones de los hechos de victimización que justifican la puesta en marcha del proceso transicional. Desde esta perspectiva, la representación del actor armado está encaminada a unas construcciones mostradas como generosas y buenas, sobre otros, se simplifica el lugar de la justicia y por tanto, 
se instrumentaliza el proceso de transición para beneficiar de manera directa a los actores armados.

- Al no corresponder con la realidad del conflicto armado, el proceso transicional en Justicia y Paz se representa también como un tema fragmentado y distante de lo que supone un cambio de orden. Vaciar de contenido social el proceso mismo incide en el refuerzo de cogniciones que tienen que ver con la naturalización del conflicto, la banalización de la vida y la escasa comprensión del fenómeno en el país.

- El cambio de orden supone unos retos para la sociedad que pasan por situar el discurso de la justicia transicional, puesto que como lo expresa Arturo Escobar $(2015)^{1}$, se sigue explicando la situación del conflicto armado desde las categorías que lo propiciaron y han venido sustentando a lo largo de 60 años. Así, el cambio implica pensar las soluciones del conflicto desde categorías que privilegien a las personas y precisamente el valor no se encuentre en el factor económico, el modelo de desarrollo neoliberal. La justicia transicional, como una de las posibles soluciones al conflicto, requiere pensar en el bienestar de las personas que han vivido la violación sistemática a los derechos humanos para alcanzar la paz.

- El proceso de Justicia y Paz ha mostrado el refuerzo del orden establecido al favorecer a los grupos terratenientes y desfavorecer a las víctimas, en una aparente judicialización de los hechos ocurridos en el marco del conflicto armado, que ha sido insuficiente.

De esta manera, la propuesta cognitiva construye una idea de actor armado ligado más al futuro y al presente que al pasado, mediante estrategias de elisión y supresión. Las consecuencias que se derivan de estos procesos inciden en proponer un sistema de representaciones que ubica al proceso de transición dentro de la lógica del valor de intercambio, instalada en las sociedades actuales.

1 Entrevista realizada en el 2015 por Esteven Navarrete para elespectador.com: http://www.elespectador.com/ noticias/economia/hay-abandonar-idea-afanosa-del-crecimiento-economico-articulo-583450 
- La activación que se hace de los Marcos de Superficie (Lakoff, 2013), construidos sobre el "sentido común" de aspectos que están ligados a la justicia transicional como los son "la justicia, la reparación, el compromiso de no repetición”, remiten a marcos profundos, asociados en este caso, a la moral que sitúa a los actores armados en un tipo de racionalidad que vacía de contenido el tema de la guerra y transforma las responsabilidades individuales de los actores armados y del estado en general.

La presencia de voces en el discurso refuerza "el principio de autoridad moral", como lo expone Lakoff (2013), para proponer cogniciones en torno a la obediencia que se debe tener con autoridades, en este caso la autoridad delegada en la ley y en un plano anterior a quienes la formularon y aprobaron, en su momento. Con esto se propende por la consolidación de un proyecto político cuyo objetivo final fue la consolidación del paramilitarismo en todo el país, justificado en la construcción simbólica del enemigo.

Por último, se evidencia que la justicia se construye como un aspecto supeditado a la acción de los actores armados y de las voces evidenciadas en el discurso y no como un derecho fundamental de todos los sujetos. En este sentido, el principio de la transición no se cumple en la medida en que la ubicación que se da a los actores en la situación del discurso afianza el orden social y político. Estos aspectos inciden en el refuerzo de la pérdida de credibilidad en la justicia y más aún en la justicia en un estado de excepcionalidad como lo es la aplicación del proceso transicional, tal y como lo muestra la realidad de los procesos de Justicia y Paz en la actualidad.

\section{CIERRE PRELIMINAR}

Hasta aquí se ha presentado cómo el proceso de transformación discursiva aporta elementos de estudio frente a la manera como en la Ley de Justicia y Paz se propende a representar a los actores armados no como partícipes de hechos de violencia sistemática, sino como pacientes-receptores de acciones positivas y como agentes de acciones positivas que beneficiarán a otros, en este caso, a las víctimas. 
Las voces que se evidencian se construyen desde el mismo enunciado ideológico, para la época de aprobación de la ley, entre 2005 y 2006.

La transformación discursiva se construye mayoritariamente sobre una estrategia de neutralización, la cual sirve al propósito de cambiar el conflicto inicial por el cual se accede a la pena alternativa y se cambia radicalmente el lugar del actor armado que ocasionó los hechos de victimización, para representarlo como un actor que “colabora”, que "se beneficia” y "conseguirá la paz y la reconciliación nacional”.

La inclusión de unos actores del conflicto, construidos sobre acciones discursivas representadas de manera positiva, incide en el refuerzo de desequilibrios en la aplicación de la justicia transicional para este momento específico de Colombia, con implicaciones sociales y políticas que, 10 años después del sometimiento a la justicia, continúan en la agenda política colombiana.

Por último, se evidencia que la justicia se construye como un aspecto supeditado a la acción de los actores armados y de las voces evidenciadas en el discurso y no como un derecho fundamental de todos los sujetos. En este sentido, el principio de la transición no se cumple en la medida en que la ubicación de los actores en la situación del discurso propende por afianzar el orden social y político. Estos aspectos inciden en el refuerzo de la pérdida de credibilidad en la justicia y más aún en la justicia en un estado de excepcionalidad como lo es la aplicación del proceso transicional, tal y como lo muestra la realidad de los procesos de Justicia y Paz en la actualidad.

Estas construcciones impiden que el proceso transicional se convierta en una oportunidad para debatir el tema central del conflicto armado que está ligado a otros conflictos sociales como la desigualdad, la impunidad y la justicia social, puesto que la representación que subyace la justicia en este caso la deja supeditada a la capacidad de agenciamiento que se otorga a los grupos armados para que se dé el proceso de reparación y construcción de paz, mientras que las víctimas son objetualizadas y ello impide que se les reconozca como actores políticos en Justicia y Paz. 


\section{REFERENCIAS}

Abric, J. (2011). Prácticas sociales y representaciones. México: Ediciones Coyoacán.

Antaqui, Ch., Billig, M., Edwards, D., y Potter, J. (2003). El análisis del discurso implica analizar. Athenea Digital, (3), 14-35, Recuperado de http://www.redalyc.org/articulo. oa?id=53700302

Bajtin, M. (2011). Estética de la creación verbal. Buenos Aires: Siglo XXI Editores.

Berger, P. y Luckmann, T. (2001). La construcción social de la realidad. Recuperado de http:// www.slideshare.net/Gatojazzy/peter-berger-thomas-luckmann-la-construccion-social -de-la-realidad

Bourdieu, P. (2000). Lo que significa hablar. Madrid: Editora Nacional.

Escobar, A. (2015). Decrecimiento, posdesarrollo y transiciones: una conversación preliminar. Interdisciplina, 3(7), 217-244, Recuperado de http://webcache.googleusercontent. $\mathrm{com} /$ search?q=cache:aCqNE4TMo5YJ:www.revistas.unam.mx/index.php/inter/article/ download/52392/46639+\&cd=10\&hl=es\&ct=clnk\&client=safari

Foucault, M. (2010). El orden del discurso. España: Fábula TusQuets Editores.

Fraser, N. (2008). Escalas de justicia. España: Herder.

García, M., Revelo, J. y Uprimny, R. (2015). Impacto constitucional e institucional de la Ley de Justicia y Paz. En López, C. (Ed.). Y refundaron la patria... de cómo mafiosos y políticos reconfiguraron el Estado colombiano, (pp. 317-330). Bogotá: Nomos Impresores.

Granada, S., Restrepo, J. y Tobón, A. (2009). Neoparamilitarismo en Colombia: una herramienta conceptual para la interpretación de dinámicas recientes del conflicto armado colombiano. En Restrepo, J. y Aponte, D. (Ed.). Guerra y violencias en Colombia: herramientas e interpretaciones, (pp. 467-469). Bogotá: Editorial Pontificia Universidad Javeriana. 
ICTJ. (2016). ¿Qué es la justicia transicional? Recuperado de https://www.ictj.org/es/ que-es-la-justicia-transicional

Jodelet, D. (1986). Las representaciones sociales: fenómenos, concepto y teoría. En Moscovici, S. (Comp). Psicología Social II, (pp. 469-494). Barcelona, Buenos Aires, México: Ediciones Paidós.

Lakoff, G. (2013). Puntos de reflexión. Manual del progresista. Barcelona: Península.

Lakoff, G. y Johnson, M. (1986). Metáforas de la vida cotidiana. Madrid: Edicones Cátedra.

López, C. (2015). Y refundaron la patria... de cómo mafiosos y politicos reconfiguraron el Estado colombiano. Bogotá: Nomos Impresores.

Moscovici, S. y Hewstone, M. (1984). De la ciencia al sentido común. En Moscovici, S. (Comp). Psicología Social II, (pp. 679-711). Barcelona, Buenos Aires, México: Ediciones Paidós.

Molano, A. (2016). A lomo de mula. Viaje al corazón de las Farc. Bogotá: Aguilar

Morris, H. y Lozano, J. (2012). Impunity. [Archivo de video]. Recuperado de https://www. youtube.com/watch?v=goZUwkldHB4

Navarrete, S. (2015, 2 de septiembre). Hay que abandonar la afanosa idea del desarrollo económico. Bogotá: El Espectador. Recuperado de https://www.elespectador.com/noticias/ economia/hay-abandonar-idea-afanosa-del-crecimiento-economico-articulo-583450

Pardo, N. (2008). ¿Qué nos dicen? ¿Qué vemos? ¿Qué es pobreza? Análisis critico de los medios. Bogotá: Antiquus editores.

Pardo, N. (2013). Violencia simbólica, discursos mediáticos y reproducción de exclusiones sociales. Discurso y Sociedad, 7(2), 416-440. Recuperado de http://www.dissoc.org/ediciones/v07n02/DS7\%282\%29Pardo.pdf 
Searle, R. (1991). Nombres propios y descripciones. En Valdés, L. M. (Comp.). La búsqueda del significado, (pp. 83-95). Madrid: Editorial Thecnos.

Semana. (2008). A los colombianos se nos corrió la frontera moral. Recuperado de http://www. semana.com/nacion/articulo/a-colombianos-corrio-frontera-moral/91837-3

Uprimny, R. (2006). ¿Justicia transicional sin transición? Verdad, justicia y reparación para Colombia. Bogotá: Ediciones Antropos.

Van Dijk, T. (2005). El discurso como interacción social. Estudios sobre el discurso II: una introducción multidisciplinaria. Barcelona: Gedisa.

Van Dijk, T. (2012). Discurso y contexto. Barcelona: Gedisa.

Van Leeuwen, T. (1996). The representation of social actors. In Caldas-Coulthard, C., \& Coulthard, M. (Eds.). Texts and practices. Readings in critical discourse analysis, (pp. 3270). Londres: Routledge.

Valencia, L. (2007). Los caminos de la alianza entre los paramilitares y los políticos. En Romero, M. (Ed.). Parapolitica. La ruta de la expansión paramilitar y los acuerdos politicos. Bogotá: Intermedio Editores. 